\title{
Notes on the vocalizations of White-throated Thrush (Turdus albicollis)
}

Peter Boesman

In the following we briefly analyze and compare voice of the different races of Whitethroated Thrush (Turdus albicollis). We also try to quantify the extent of any vocal differences using the criteria proposed by Tobias et al. (2010), as a support for taxonomic review. We have made use of sound recordings available on-line from Xeno Canto (XC).

A comparison of song of the different groups, illustrated with multiple sonograms.

\section{assimilis group}

Song is delivered at a very regular pace, typically changing notes all the time, but many repeated 2 or 3 times. Also fast-paced repeats. Note shapes are highly variable. Most notes are in the range $1.5-3.5 \mathrm{kHz}$, occasionally higher. Overall freq. range c.2-3kHz., freq. range of most notes $1-2 \mathrm{kHz}$.

Mexico
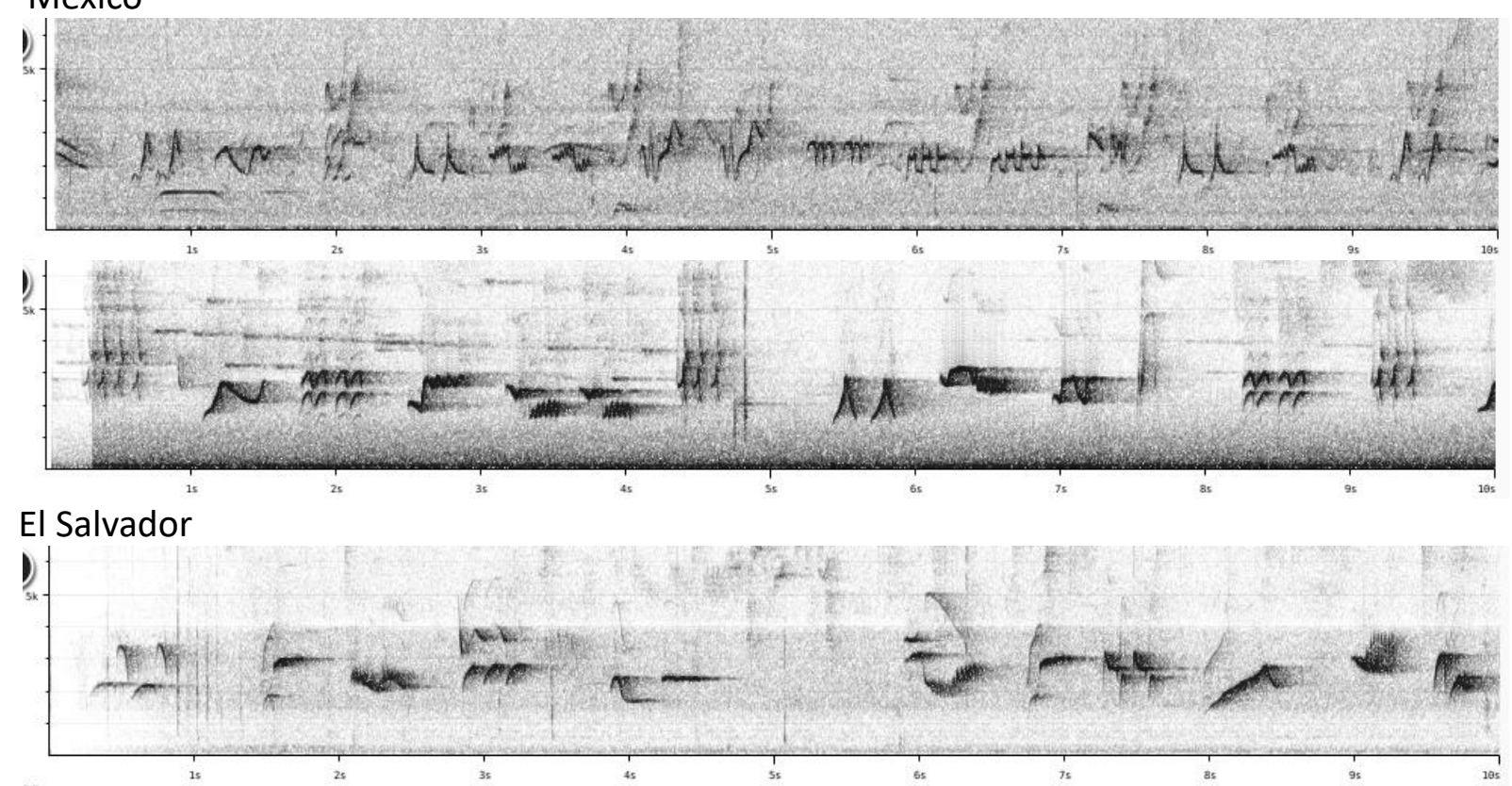

Coiba island

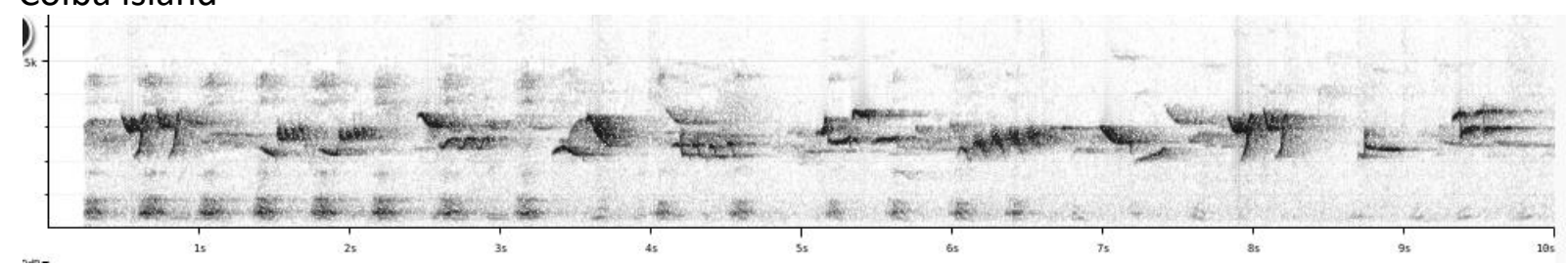




\section{HANDBOOK OF THE

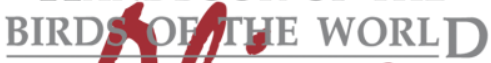 \\ Aluve}

\section{ORNITHOLOGICAL NOTES}

\section{daguae (Darien to W Ecuador)}

Song is a continuous series ('caroling') of throaty whistles at rather flat pitch. Note shapes vary little, and overall freq. range is small, c. $1.5-2 \mathrm{kHz}$. Freq. range of most notes c. $0.5-1 \mathrm{kHz}$. Pace about 1.3-1.4notes/s.

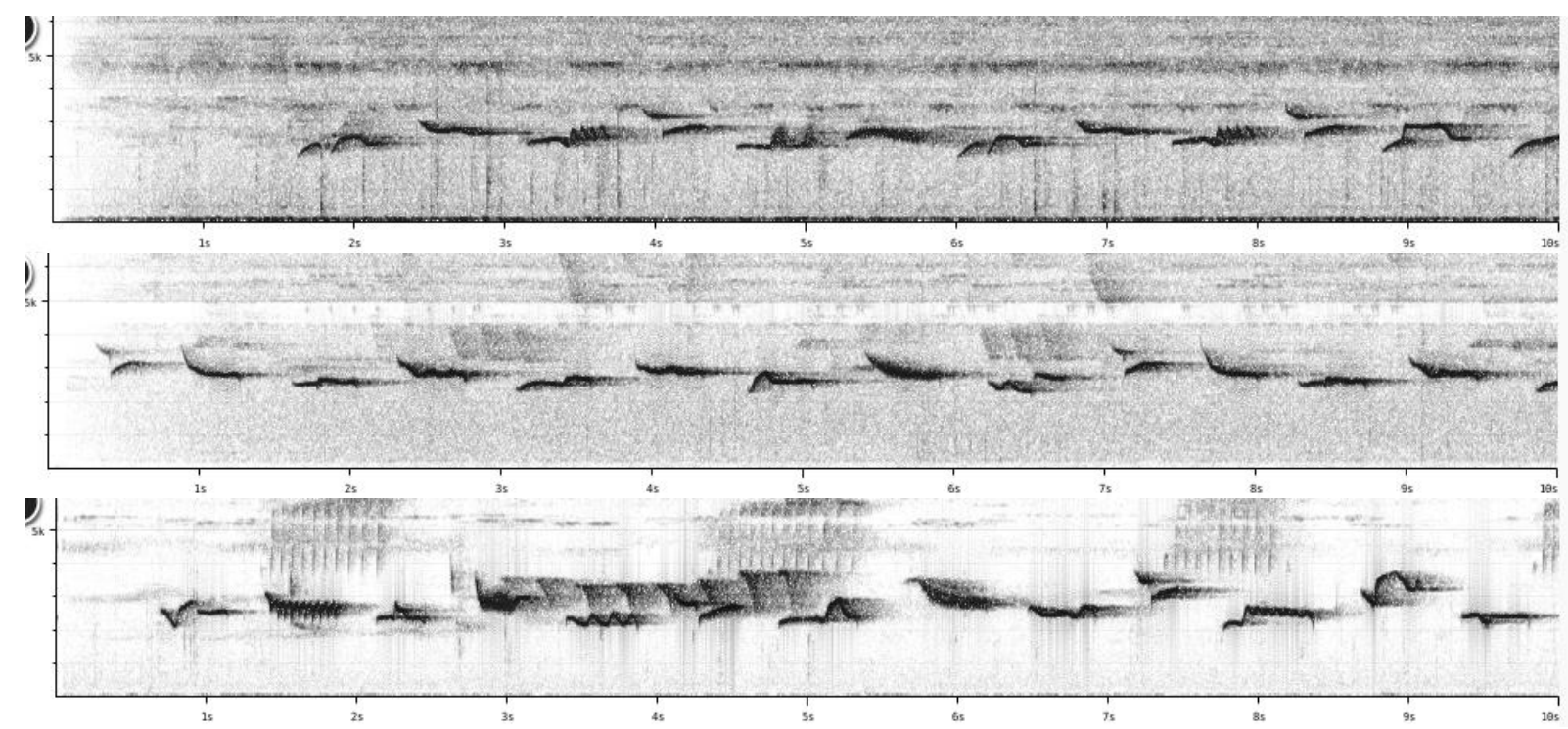

Northern South America group (E of Andes)

Song is a continuous series ('caroling') of throaty whistles at very flat pitch. Note shapes vary little, and overall freq. range very small, c. $1.5-2 \mathrm{kHz}$. Freq. range of most notes c. $0.1-0.8 \mathrm{kHz}$. Similar to daguae, but even narrower freq. range, with notes and pauses in between notes more uniform in duration (much less short or double notes). Some note shapes however identical. Pace about 1-1.2notes/s.

$\mathrm{N}$ Venezuela

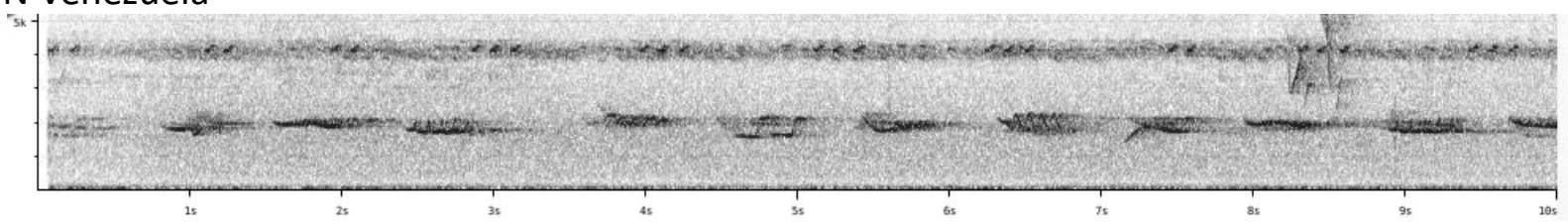

Trinidad

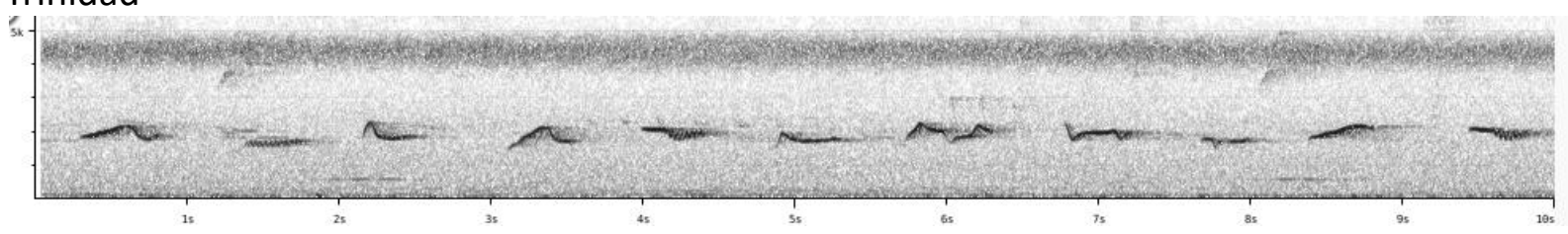

Suriname

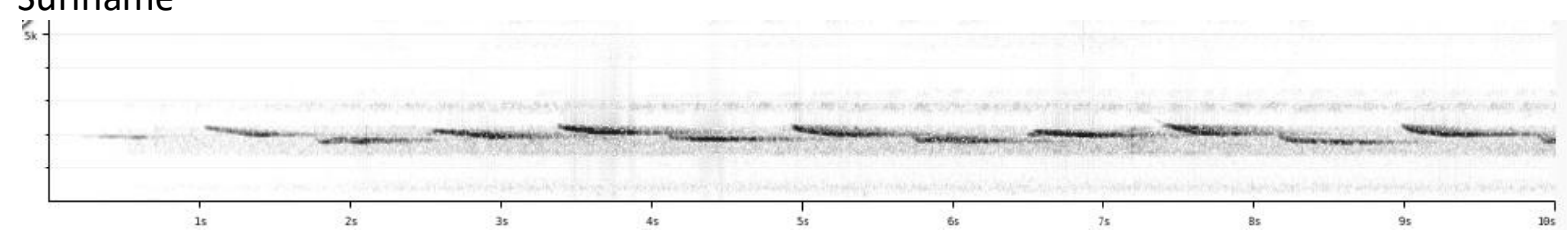




\section{HANDBOOK OF THE \\ BIRDS PF/THE WORLD}

\section{ORNITHOLOGICAL NOTES}

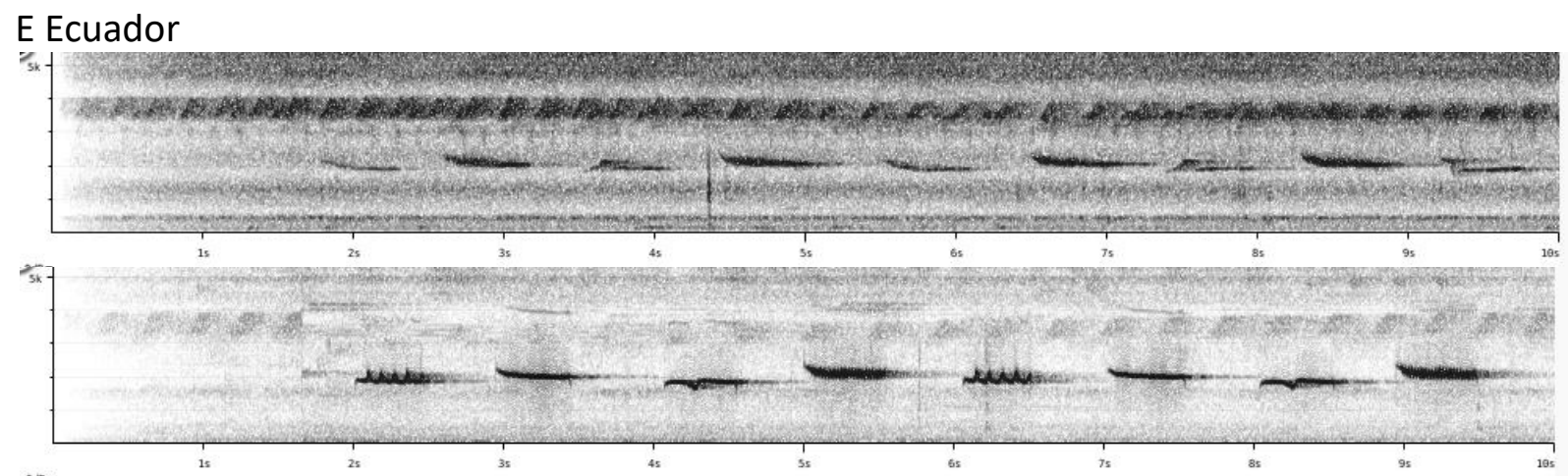

SE Colombia

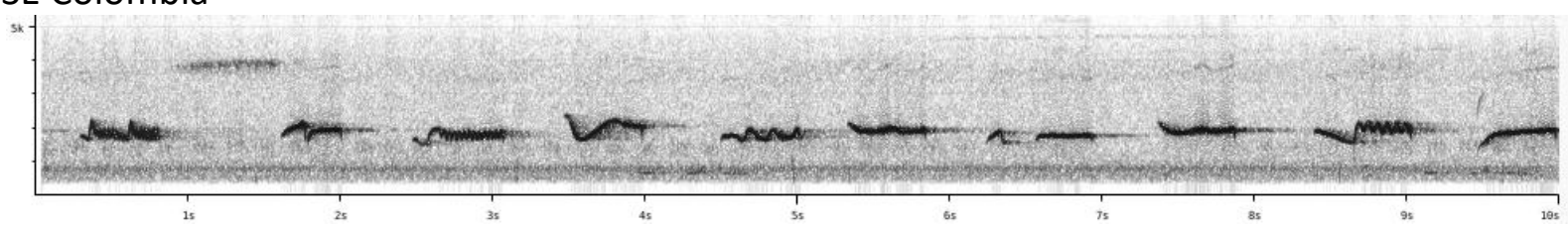

Rondonia
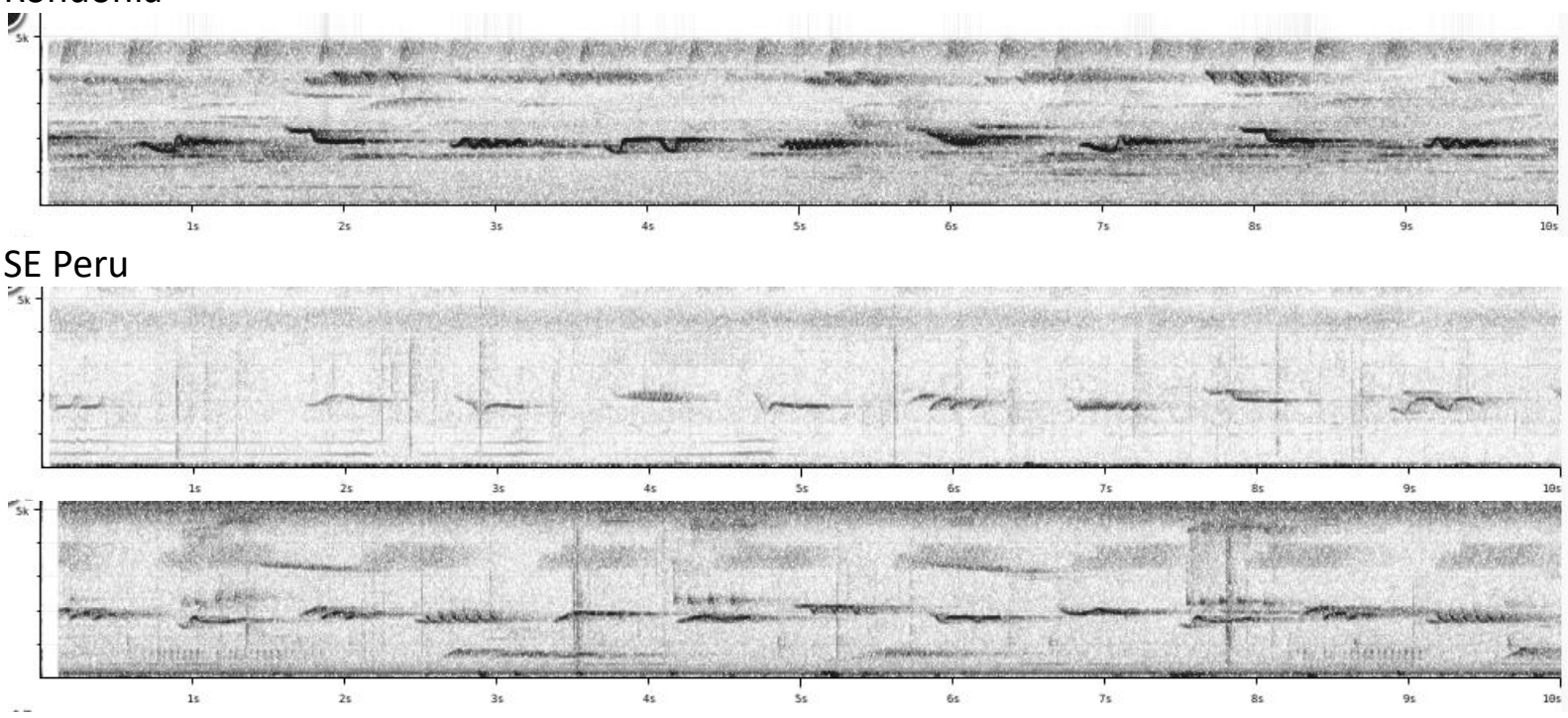

Eastern South America group (mainly E Brazil)

Song is a continuous series ('caroling') of throaty whistles at rather flat pitch. Note shapes vary quite a bit, and overall freq. range quite small, c. $1.5-2.5 \mathrm{kHz}$. Freq. range of most notes c.0.3-1.1 kHz. Similar to daguae, with short notes and double notes thrown in. Pace about 1.1-1.3notes/s.

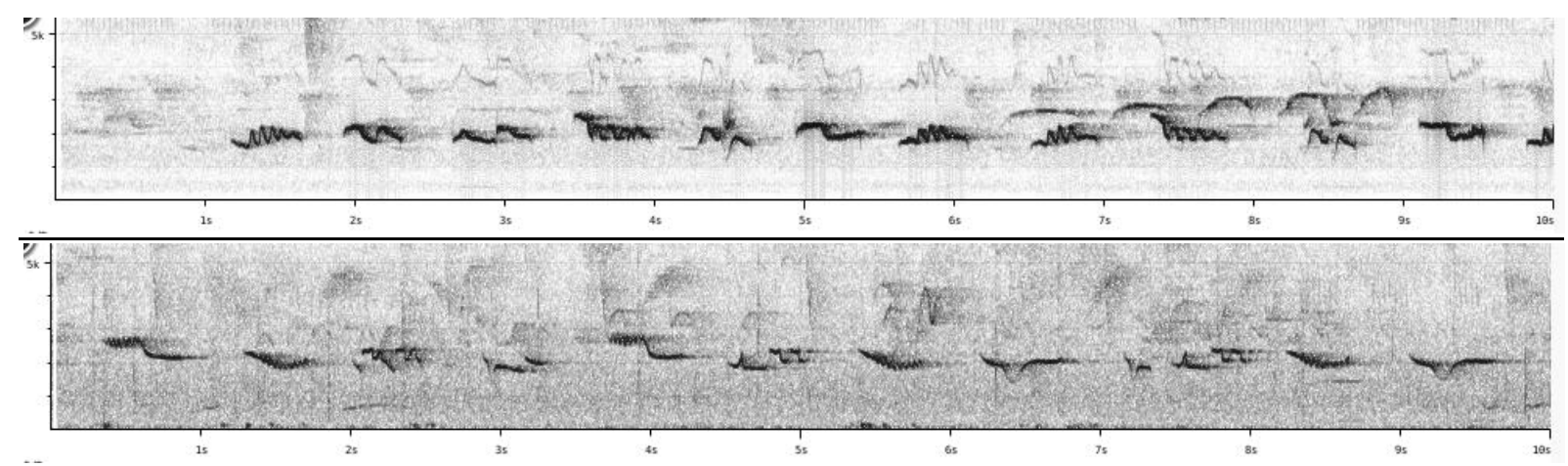




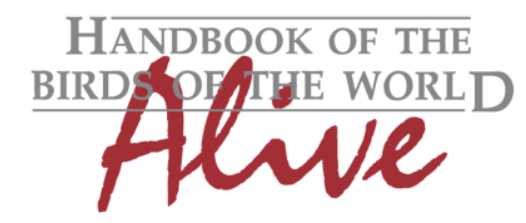

\section{ORNITHOLOGICAL NOTES}
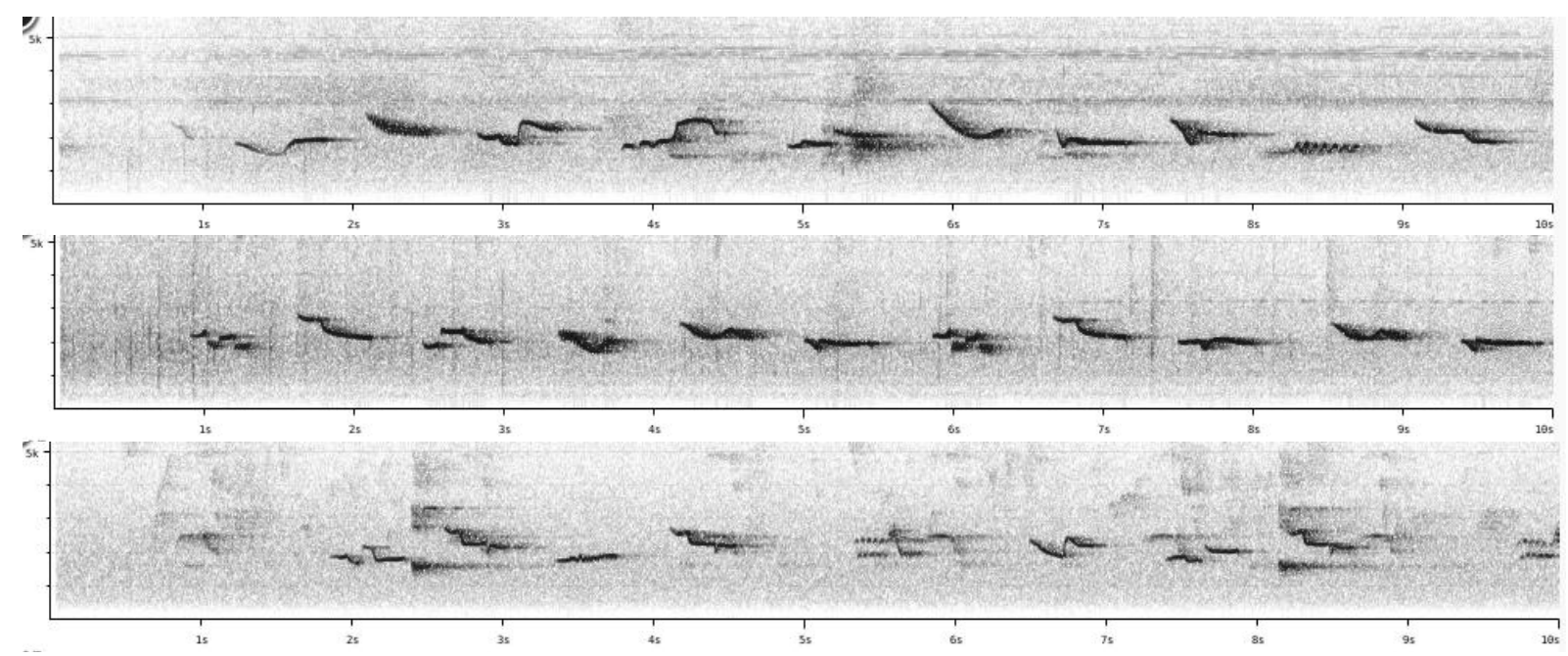

From the above examples, it is quite clear that the assimilis group is vocally the most distinctive, clearly different from the three other groups: a much higher pace (score 2-3), shorter notes (score 1-2), which are more variable (score 1) and often with repeats 2-4 times (score 3). Also a larger frequency range (score 2-3). When applying Tobias criteria, this would lead to a total vocal score of about 5-6.

The other three groups are vocally much more similar:

'Northern South America group' has the slowest pace (score 1), narrowest freq. range (score 2) of both overall song and individual notes. Total score 3.

'Eastern South America group' and daguae are much harder to distinguish. daguae has a slightly higher pace. Score 1-2.

I didn't download all recordings to make precise measurements of all basic sound parameters on a large set of recordings, but the above examples are quite convincing. I also did not investigate call notes, which may contain additional information on the vocal difference of the four groups.

This note was finalized on 19th April 2016, using sound recordings available on-line at that moment. We would like to thank in particular the sound recordists who placed their recordings for this species on XC.

\section{References}

Tobias, J.A., Seddon, N., Spottiswoode, C.N., Pilgrim, J.D., Fishpool, L.D.C. \& Collar, N.J. (2010). Quantitative criteria for species delimitation. Ibis 152(4): 724-746.

\section{Recommended citation}

Boesman, P. (2016). Notes on the vocalizations of White-throated Thrush (Turdus albicollis). HBW Alive Ornithological Note 305. In: Handbook of the Birds of the World Alive. Lynx Edicions, Barcelona. (retrieved from http://www.hbw.com/node/1251761 on 14 October 2016). 